\title{
Polymorphisms of rs1347093 and rs1397529 are associated with lung cancer risk in northeast Chinese population
}

\author{
Xiaoying Li ${ }^{1,2}$, Xuelian Li ${ }^{1,2}$, Yangwu Ren ${ }^{1,2}$, Zhihua Yin ${ }^{1,2}$, Xiaowei Quan ${ }^{1,2}$, Xiaoxia \\ $\mathrm{Xue}^{3}$ and Baosen Zhou ${ }^{1,2}$ \\ ${ }^{1}$ Department of Epidemiology, School of Public Health, China Medical University, Shenyang, China \\ ${ }^{2}$ Key Laboratory of Cancer Etiology and Prevention (China Medical University), Liaoning Provincial Department of Education, \\ Liaoning, China \\ ${ }^{3}$ The Third Center of Laboratory Technology and Experimental Medicine, China Medical University, Shenyang, China \\ Correspondence to: Baosen Zhou, email: bszhou@cmu.edu.cn
}

Keywords: single nucleotide polymorphisms; MIR217HG; Gabl; lung cancer; susceptibility

Accepted: September 23, 2017

Published: October 24, 2017

Copyright: Li et al. This is an open-access article distributed under the terms of the Creative Commons Attribution License 3.0 (CC BY 3.0), which permits unrestricted use, distribution, and reproduction in any medium, provided the original author and source are credited.

\section{ABSTRACT}

Lung cancer is one of the malignant tumors with the highest morbidity and mortality all over the world. Here we researched the association between two SNPs (rs1347093 in MIR217HG and rs1397529 in Gab1) and the risk of lung cancer in northeast Chinese population, including 825 cases and 766 controls. We carried out $\mathrm{X}^{2}$ test, unconditional logistic regression analysis and crossover analysis to estimate the relationship between SNPs and lung cancer risk and the interaction between SNPS and smoking on susceptibility to lung cancer. The results indicated that rs1347093, rs1397529 polymorphisms were associated with lung cancer risk, especially with adenocarcinoma risk. Dominant genetic model of the rs1347093 was associated with reduced risk of lung cancer compared to CC genotype (AC+AA vs. CC: adjusted OR $=0.599,95 \% \mathrm{CI}=0.418-0.858, P=0.005)$. For rs1347093, the similar result was found. Dominant genetic model of the rs1397529 was associated with reduced risk of lung cancer compared to AA genotype (AC+CC vs. AA: adjusted $\mathrm{OR}=0.664,95 \% \mathrm{CI}$ $=0.491-0.897, P=0.008)$. There is no significant interaction between rs1347093, rs1397529 polymorphism and smoking on susceptibility to lung cancer. Our study might demonstrate that rs1347093 in MIR217HG and rs1397529 in Gab1 could be meaningful as the novel biomarker for lung cancer risk.

\section{INTRODUCTION}

According to the latest cancer statistics, lung cancer is one of the malignant tumors with the highest morbidity and mortality all over the world [1-3]. Approximate 14.1 million new cancer cases occurred in 2012, including about 1.8 million lung cancer cases, which constituted about $12.8 \%$ of all new cancer cases [3]. As we all know, the leading risk factor for lung cancer is smoking [4]. However, more and more studies indicate that genetic risk factors may also play an important part in the occurrence and development of lung cancer [5-7]. Meanwhile, the interaction between genes and smoking may exist.
Therefore, this study intended to explore the association between single nucleotide polymorphisms (SNPs) and the susceptibility of lung cancer, and the interaction between SNPs and smoking on lung cancer risk.

MIR217HG (MIR217 host gene) is located in $2 p 16$. It is the host gene of MIR217. Some previous studies demonstrate that MIR217 is closely related to the occurrence and development of tumor. For example, N. A. Schultz et al [8] proved the diagnostic MIR217 expression profile associated with pancreatic cancer, which was described by Szafranska et al [9]. However, up to now, there are no reports about the function of MIR217HG and the association between MIR217HG and any diseases. 
The Gab-family adapter proteins are also known as the Grb2-associated binder family adapter proteins, which are scaffolding adapter molecules [10]. Gab proteins mainly consist of Gab1, Gab2 and Gab3 [11]. The weights of Gab1 molecules are 100-120KD [12, 13]. Gab1 is located in $4 \mathrm{q} 31$ and it most mainly exists in brain, kidney, lung, heart, testis, and ovary [13, 14]. According to previous studies [13, 15], Gab1 worked in EGF receptor / ErbB-mediated cell transformation, which indicated that Gab1 played an important role in oncogenic signaling pathways. Fan Y et al [16] found that Gab1 had the overexpression in chondrosarcoma tissues, which made Gab1 be considered as a novel biomarker of diagnosis and prognosis of chondrosarcoma. The study of Bai R et al [17] indicated that Gab1 played a role in the function exertion of miR-409-3p, which was considered as a metastatic suppressor. However, to the best of my knowledge, no study about the association between Gab1 and lung cancer was carried out.

Given that the relationship between MIR217HG, Gab1 and lung cancer was undefined, the present study evaluated the relationship between MIR217HGrs1347093, Gab1-rs1397529 polymorphisms and lung cancer susceptibility and investigated the interaction between MIR217HG-rs1347093, Gab1-rs1397529 polymorphisms and smoking status on the risk of lung cancer, which could provide a new strategy of lung cancer screening in Chinese population.

\section{RESULTS}

\section{Baseline characteristics}

The demographic characteristics of 825 cases and 766 controls were shown in Table 1 . In case group, there were 483 cases of adenocarcinoma, 207 cases of squamous cell carcinoma, 95 cases of small cell lung cancer and 40 cases of other histological type. There was no significant difference in the distribution of age $(P=0.197)$ between lung cancer patients and controls with the mean age for cases and controls were $58.567 \pm 11.054$ and $57.158 \pm$ 13.341 respectively. However, there was a significant difference in the distributions of gender and smoking (both were $P<0.001)$. Therefore, the further study was adjusted by gender, age and smoking.

\section{The distributions of genotypes, alleles and associations with lung cancer}

Distributions of rs1347093, rs1397529 genotypes and alleles among subjects and their associations with the risk of lung cancer were summarized in Table 2. The observed genotype frequencies of rs1347093, rs1397529 among controls was in agreement with Hardy-Weinberg equilibrium $\left(\chi^{2}=0.984, P=0.321\right.$ for rs $1347093 ; \chi^{2}=$
$0.154, P=0.695$ for rs1397529). For the distribution of rs1347093, A allele had the relationship with a significantly reduced risk of lung cancer (adjusted OR = $0.619,95 \% \mathrm{CI}=0.436-0.877, P=0.007)$, compared with $\mathrm{C}$ allele. Meanwhile, AC genotype of the rs1347093 was linked to reduced risk of lung cancer compared to $\mathrm{CC}$ genotype (AC vs. CC: adjusted OR $=0.594$, $95 \% \mathrm{CI}=0.413-0.853, P=0.005)$. Besides, we observed that a significant association between the rs1347093 polymorphism and reduced risk of lung cancer existed in a dominant genetic model, assuming that the variant genotypes (AC+AA) was the dominant genetic model $(\mathrm{AC}+\mathrm{AA}$ vs. $\mathrm{CC}$ : adjusted $\mathrm{OR}=0.599,95 \% \mathrm{CI}=0.418-$ $0.858, P=0.005)$. For the distribution of rs1397529, $\mathrm{C}$ allele had the relationship with a significantly reduced risk of lung cancer (adjusted $\mathrm{OR}=0.697,95 \% \mathrm{CI}=0.526$ 0.926, $P=0.013$ ), compared with A allele. Meanwhile, a significant association between the rs1397529 polymorphism and reduced risk of lung cancer in one genetic model could be observed (AC vs. AA: adjusted $\mathrm{OR}=0.649,95 \% \mathrm{CI}=0.476-0.884, P=0.006)$. Besides, we observed that a significant association between the rs1397529 polymorphism and reduced risk of lung cancer existed in a dominant genetic model, assuming that the variant genotypes $(\mathrm{AC}+\mathrm{CC})$ was the dominant genetic model $(\mathrm{AC}+\mathrm{CC}$ vs. $\mathrm{AA}$ : adjusted $\mathrm{OR}=0.664,95 \% \mathrm{CI}=$ 0.491-0.897, $P=0.008)$.

\section{Stratification analyses}

In order to further study the relationship between rs1347093, rs1397529 polymorphism and lung cancer risk, we conducted several stratification analyses in the dominant genetic model. As shown in Table 3, AA/AC genotype of rs1347093 had the relationship with a significantly decreased risk of lung cancer in adenocarcinoma subgroup (adjusted OR $=0.598,95 \% \mathrm{CI}$ $=0.393-0.912, P=0.017$ ) and small cell lung cancer subgroup (adjusted OR $=0.296,95 \% \mathrm{CI}=0.106-0.826$, $P=0.020$ ), compared with $\mathrm{CC}$ genotype. There was no significant association between the dominant genetic model of rs1347093 and the susceptibility of lung cancer in squamous cell carcinoma subgroup. For rs1397529, CC/ AC genotype was linked with a significantly decreased risk of lung cancer in adenocarcinoma subgroup (adjusted $\mathrm{OR}=0.689,95 \% \mathrm{CI}=0.488-0.974, P=0.035)$, compared with AA genotype. We failed to observe a significant association between the dominant genetic model of rs1397529 and the susceptibility of lung cancer in squamous cell carcinoma subgroup and small cell lung cancer subgroup.

Table 4 summarized the associations between rs1347093, rs1397529 polymorphism and lung cancer risk, stratified by clinical stages. We could obtain a significant association between AA/AC genotype 
Table 1: Demographics of the study subjects

\begin{tabular}{|c|c|c|c|}
\hline Characteristics & Cases n(\%) & Controls n(\%) & $P$ \\
\hline Gender & & & $<0.001$ \\
\hline Female & $619(75.0)$ & $658(85.9)$ & \\
\hline Male & $206(25.0)$ & $108(14.1)$ & \\
\hline Age (years) & $58.567 \pm 11.054$ & $57.158 \pm 13.341$ & 0.197 \\
\hline \multicolumn{4}{|l|}{ Stage* $^{*}$} \\
\hline I & $52(7.8)$ & & \\
\hline II & $132(19.9)$ & & \\
\hline III & $331(49.9)$ & & \\
\hline IV & $149(22.4)$ & & \\
\hline \multicolumn{4}{|l|}{ Histological type } \\
\hline Adenocarcinoma & $483(58.5)$ & & \\
\hline Squamous cell carcinoma & $207(25.1)$ & & \\
\hline Small cell lung cancer & $95(11.5)$ & & \\
\hline other & $40(4.9)$ & & \\
\hline Family history of cancer* & & & 0.912 \\
\hline yes & $68(12.6)$ & $82(12.8)$ & \\
\hline no & $471(87.4)$ & $557(87.2)$ & \\
\hline Smoking & & & $<0.001$ \\
\hline yes & $183(22.2)$ & $54(7.0)$ & \\
\hline no & $642(77.8)$ & $712(93.0)$ & \\
\hline
\end{tabular}

*There are missing values.

Table 2: Distributions of rs1347093, rs1397529 genotypes and alleles among lung cancer cases and controls and their associations with the risk of lung cancer

\begin{tabular}{|c|c|c|c|c|c|c|}
\hline Genotype & Cases n(\%) & Controls n(\%) & $P$ & OR [5] & $P$ adj & $\mathrm{OR}[95 \% \mathrm{CI}]$ adj \\
\hline \multicolumn{7}{|l|}{ rs1347093 } \\
\hline $\mathrm{CC}$ & $768(93.1)$ & $680(88.8)$ & & 1.00 (ref) & & 1.00 (ref) \\
\hline $\mathrm{AC}$ & $56(6.8)$ & $85(11.1)$ & 0.003 & $0.583(0.410,0.830)$ & 0.005 & $0.594(0.413,0.853)$ \\
\hline AA & $1(0.1)$ & $1(0.1)$ & 0.931 & $0.885(0.055,14.183)$ & 0.978 & $1.040(0.065,16.667)$ \\
\hline $\mathrm{AC} / \mathrm{AA}$ & $57(6.9)$ & $86(11.2)$ & 0.003 & $0.587(0.413,0.833)$ & 0.005 & $0.599(0.418,0.858)$ \\
\hline $\mathrm{C}$ & $1592(96.5)$ & $1445(94.3)$ & & 1.00 (ref) & & 1.00 (ref) \\
\hline A & $58(3.5)$ & $87(5.7)$ & 0.004 & $0.605(0.431,0.850)$ & 0.007 & $0.619(0.436,0.877)$ \\
\hline \multicolumn{7}{|l|}{ rs1397529 } \\
\hline AA & $736(89.2)$ & $646(84.3)$ & & 1.00 (ref) & & 1.00 (ref) \\
\hline $\mathrm{AC}$ & $83(10.1)$ & $114(14.9)$ & 0.004 & $0.639(0.473,0.864)$ & 0.006 & $0.649(0.476,0.884)$ \\
\hline $\mathrm{CC}$ & $6(0.7)$ & $6(0.8)$ & 0.822 & $0.878(0.282,2.735)$ & 0.944 & $0.959(0.303,3.039)$ \\
\hline $\mathrm{AC} / \mathrm{CC}$ & $89(10.8)$ & $120(15.7)$ & 0.004 & $0.651(0.485,0.873)$ & 0.008 & $0.664(0.491,0.897)$ \\
\hline A & $1555(94.2)$ & $1406(91.8)$ & & 1.00 (ref) & & 1.00 (ref) \\
\hline $\mathrm{C}$ & $95(5.8)$ & $126(8.2)$ & 0.006 & $0.682(0.517,0.898)$ & 0.013 & $0.697(0.526,0.926)$ \\
\hline
\end{tabular}

$P$ adj and $\mathrm{OR}[95 \% \mathrm{CI}]$ adj were adjusted for age, gender and smoking. 
Table 3: The effect of the SNPs rs1347093 and rs1397529 in the region on lung cancer risk in pathological subgroup

\begin{tabular}{lllclll}
\hline Genotype & Cases n(\%) & Controls n(\%) & $\begin{array}{c}P \\
\text { value }\end{array}$ & OR(95\%CI) & $P$ adj & OR(95\%CI) adj \\
\hline
\end{tabular}

rs 1347093

Adenocarcinomas

$\begin{array}{lcccccc}\mathrm{CC} & 450(93.2) & 680(88.8) & & 1.00(\mathrm{ref}) & 1.00(\mathrm{ref}) & 0.598(0.393,0.912) \\ \mathrm{AA} / \mathrm{AC} & 33(6.8) & 86(11.2) & 0.011 & 0.580(0.382,0.881) & 0.017 & 0.59\end{array}$

Squamous cell carcinoma

$\mathrm{CC}$

188(90.8)

$\mathrm{AA} / \mathrm{AC}$

19(9.2)

$680(88.8)$

$86(11.2)$

680(88.8)

91(95.8)

$86(11.2)$

4(4.2)

$\mathrm{AA} / \mathrm{AC}$

rs1397529

Adenocarcinomas

AA

429(88.8)

646(84.3)

54(11.2)

$\mathrm{AC} / \mathrm{CC}$

Squamous cell carcinoma

AA

186(89.9)

$\mathrm{AC} / \mathrm{CC}$

21(10.1)

$646(84.3)$

120(15.7)

646(84.3)

1.00 (ref)

120(15.7)

0.066

$0.495(0.234,1.048)$

Small cell lung cancer

$\mathrm{AC} / \mathrm{CC}$

$8(8.4)$
1.00 (ref)

$0.678(0.481,0.955)$

1.00 (ref)

$0.047 \quad 0.608(0.372,0.994)$

0.171

0.686(0.401,1.176)

$P$ adj and $\mathrm{OR}[95 \% \mathrm{CI}]$ adj were adjusted for age, gender and smoking.

of rs1347093 and reduced risk of lung cancer in comparison with CC genotype in stage III+ IV subgroup (adjusted $\mathrm{OR}=0.568,95 \% \mathrm{CI}=0.368-0.876, P=0.011$ ). Meanwhile, we also observed that $\mathrm{CC} / \mathrm{AC}$ genotype of rs1397529 was associated with reduced risk of lung cancer in comparison with AA genotype in stage III+ IV subgroup (adjusted OR $=0.647,95 \% \mathrm{CI}=0.452-0.925$, $P=0.017)$.

Table 5 showed the associations between rs1347093, rs1397529 polymorphism and lung cancer risk, stratified by smoking. We observed a significant association between AA/AC genotype of rs1347093 and reduced risk of lung cancer in both smoking subgroup and nonsmoking subgroup, compared with CC genotype (smoking subgroup: adjusted $\mathrm{OR}=0.664,95 \% \mathrm{CI}=0.491-0.897$, $P=0.008$; non-smoking subgroup: adjusted $\mathrm{OR}=0.559$, $95 \% \mathrm{CI}=0.380-0.823, P=0.003)$. We also observed that $\mathrm{CC} / \mathrm{AC}$ genotype of rs1397529 was linked to reduced risk of lung cancer in non-smoking subgroup, compared with AA genotype (adjusted $\mathrm{OR}=0.595,95 \% \mathrm{CI}=0.430$ $0.822, P=0.002)$.
Table 6 listed the associations between rs1347093, rs1397529 polymorphism and lung cancer risk, stratified by gender. We observed a significant association between AA/AC genotype of rs1347093 and reduced risk of lung cancer in comparison with $\mathrm{CC}$ genotype in the female subgroup (adjusted $\mathrm{OR}=0.582,95 \% \mathrm{CI}=0.391-0.866$, $P=0.008)$. We also found that $\mathrm{CC} / \mathrm{AC}$ genotype of rs1397529 was associated with reduced risk of lung cancer in comparison with AA genotype in the female subgroup (adjusted $\mathrm{OR}=0.605,95 \% \mathrm{CI}=0.432-0.847, P=0.003$ ).

\section{Interaction between rs1347093, rs1397529 and smoking}

The results of crossover analysis were listed in Tables 7 and 8 . We could find that there was no significant interaction between rs1347093, rs1397529 and smoking on lung cancer risk. The logistic regression model also demonstrated that interaction didn't exist between rs1347093, rs1397529 and smoking on risk of lung cancer (Table 9). 
Table 4: Associations between rs134709, rs1397529 polymorphisms and lung cancer susceptibility, stratified by stages

\begin{tabular}{|c|c|c|c|c|c|c|}
\hline Genotype & Cases n(\%) & Controls n(\%) & $P$ & OR(95\%CI) & Padj & OR(95\%CI) adj \\
\hline \multicolumn{7}{|l|}{ rs 1347093} \\
\hline \multicolumn{7}{|l|}{ stage I+II } \\
\hline $\mathrm{CC}$ & $169(91.8)$ & $680(88.8)$ & & 1(ref) & & 1 (ref) \\
\hline $\mathrm{AA} / \mathrm{AC}$ & $15(8.2)$ & $86(11.2)$ & 0.226 & $0.702(0.395,1.246)$ & 0.232 & $0.700(0.390,1.256)$ \\
\hline \multicolumn{7}{|l|}{$\begin{array}{l}\text { stage III+ } \\
\text { IV }\end{array}$} \\
\hline $\mathrm{CC}$ & $449(93.5)$ & $680(88.8)$ & & 1(ref) & & 1 (ref) \\
\hline $\mathrm{AA} / \mathrm{AC}$ & $31(6.5)$ & $86(11.2)$ & 0.006 & $0.546(0.356,0.837)$ & 0.011 & $0.568(0.368,0.876)$ \\
\hline \multicolumn{7}{|l|}{ rs1397529 } \\
\hline \multicolumn{7}{|l|}{ stage I+II } \\
\hline AA & $165(89.7)$ & $646(84.3)$ & & $1(\mathrm{ref})$ & & $1(\mathrm{ref})$ \\
\hline $\mathrm{AC} / \mathrm{CC}$ & $19(10.3)$ & $120(15.7)$ & 0.068 & $0.620(0.371,1.036)$ & 0.111 & $0.655(0.390,1.102)$ \\
\hline \multicolumn{7}{|l|}{$\begin{array}{l}\text { stage III+ } \\
\text { IV }\end{array}$} \\
\hline AA & $431(89.8)$ & $646(84.3)$ & & 1(ref) & & 1 (ref) \\
\hline $\mathrm{AC} / \mathrm{CC}$ & $49(10.2)$ & $120(15.7)$ & 0.007 & $0.612(0.430,0.872)$ & 0.017 & $0.647(0.452,0.925)$ \\
\hline
\end{tabular}

$P$ adj and $\mathrm{OR}[95 \% \mathrm{CI}]$ adj were adjusted for age, gender and smoking.

\section{DISCUSSION}

In recent years, more and more studies about the association between SNPs and lung cancer risk were conducted. The studies of Chen D [18], Xie K [19], Yin $\mathrm{Z}[20]$ et al all came to a significant conclusion. SNPs play an important role in the occurrence, development and prognosis of lung cancer [21]. In the present study, we evaluated the association between rs1347093, rs1397529 polymorphisms and lung cancer susceptibility by the statistical method in 825 cases and 766 controls. The results of the study indicated that rs1347093, rs1397529 polymorphisms were associated with lung cancer risk, especially with adenocarcinoma risk. For rs1347093 in MIR217HG, the individuals who carry the dominant genetic model $(\mathrm{AC}+\mathrm{AA})$ have less risk of lung cancer than those who carry CC genotype. For rs1397529 in Gab1, the individuals who carry the dominant genetic model $(\mathrm{AC}+\mathrm{CC})$ have less risk of lung cancer than those who carry AA genotype. In stratification analyses by histological type, we found that the individuals who carry the dominant genetic model of rs1347093, rs1397529 have less risk of adenocarcinoma, compared with those individuals who don't carry the dominant genetic model of rs1347093, rs1397529. For rs1347093, the similar result was found in small cell lung cancer subgroup. The individuals who carry the dominant genetic model
$(\mathrm{AC}+\mathrm{CC})$ have less risk of small cell lung cancer than those who carry AA genotype. The stratification analysis showed that the association of rs1347093, rs 1397529 to risk of lung cancer was mainly derived from female. This may be on account of differences of men and women in the physiological and genetic aspects. We will research this issue further in the later study. We also researched interaction between rs1347093, rs1397529 and smoking on lung cancer risk. However, the results indicated that the interaction didn't exist. One of the reasons may be that the number of subjects with the exposure of tobacco is not large enough to get a statistically significant difference.

rs 1347093 is located in the intron region of MIR217HG, and rs1397529 is located in the UTR3 region of Gab1. Although they can't code proteins, they might have regulating effects, which might have an effect on gene function. Thus rs1347093, rs1397529 polymorphisms might influence the function of genes and might have the relationship with diseases. The function of rs1347093 and rs1397529 will be studied in our future study. Gab1 is a docking protein, which can transduce signals from all various tyrosine kinases [22]. Expression of Gab1 is associated with many cancer, such as ovarian cancer [23], breast cancer [22], chondrosarcoma [16], colorectal cancer [17], urothelial cell carcinoma [24] and so on. MIR217HG is the host gene of MIR217. Although the function of MIR217HG 
Table 5: Associations between rs1347093, rs1397529 polymorphisms and lung cancer susceptibility, stratified by smoking status

\begin{tabular}{|c|c|c|c|c|c|c|}
\hline Genotypes & Cases n(\%) & Controls n(\%) & $\boldsymbol{P}$ & OR $[95 \% \mathrm{CI}]$ & $P$ adj & OR $[95 \% C I]$ adj \\
\hline \multicolumn{7}{|l|}{ rs1347093 } \\
\hline \multicolumn{7}{|l|}{$\begin{array}{l}\text { Non- } \\
\text { exposed }\end{array}$} \\
\hline $\mathrm{CC}$ & $599(93.3)$ & $630(88.5)$ & & 1(ref) & & 1 (ref) \\
\hline $\mathrm{AC} / \mathrm{AA}$ & $43(6.7)$ & $82(11.5)$ & 0.002 & $0.552(0.375,0.811)$ & 0.003 & $0.559(0.380,0.823)$ \\
\hline \multicolumn{7}{|l|}{ Exposed } \\
\hline $\mathrm{CC}$ & $169(92.3)$ & $50(92.6)$ & & 1(ref) & & 1 (ref) \\
\hline $\mathrm{AC} / \mathrm{AA}$ & $14(7.7)$ & $4(7.4)$ & 0.004 & $0.651(0.485,0.873)$ & 0.008 & $0.664(0.491,0.897)$ \\
\hline \multicolumn{7}{|l|}{ rs1397529 } \\
\hline \multicolumn{7}{|l|}{$\begin{array}{l}\text { Non- } \\
\text { exposed }\end{array}$} \\
\hline $\mathrm{AA}$ & $576(89.7)$ & $596(83.7)$ & & $1(\mathrm{ref})$ & & 1(ref) \\
\hline $\mathrm{AC} / \mathrm{CC}$ & $66(10.3)$ & $116(16.3)$ & 0.001 & $0.589(0.426,0.813)$ & 0.002 & $0.595(0.430,0.822)$ \\
\hline \multicolumn{7}{|l|}{ Exposed } \\
\hline AA & $160(87.4)$ & $50(92.6)$ & & $1(\mathrm{ref})$ & & 1(ref) \\
\hline $\mathrm{AC} / \mathrm{CC}$ & $23(12.6)$ & $4(7.4)$ & 0.300 & $1.797(0.593,5.443)$ & 0.301 & $1.800(0.591,5.478)$ \\
\hline
\end{tabular}

$P$ adj and $\mathrm{OR}[95 \% \mathrm{CI}]$ adj were adjusted for age and gender.

Table 6: Associations between rs1347093, rs1397529 polymorphisms and lung cancer susceptibility, stratified by gender

\begin{tabular}{|c|c|c|c|c|c|c|}
\hline Genotypes & Cases n(\%) & Controls n(\%) & $P$ & OR $[95 \% C I]$ & $P$ adj & OR $[95 \% C I]$ adj \\
\hline \multicolumn{7}{|l|}{ rs1347093 } \\
\hline \multicolumn{7}{|l|}{ Female } \\
\hline $\mathrm{CC}$ & $576(93.1)$ & $584(88.8)$ & & 1 (ref) & & 1 (ref) \\
\hline $\mathrm{AC} / \mathrm{AA}$ & $43(6.9)$ & $74(11.2)$ & 0.008 & $0.589(0.398,0.873)$ & 0.008 & $0.582(0.391,0.866)$ \\
\hline \multicolumn{7}{|l|}{ Male } \\
\hline $\mathrm{CC}$ & 192(93.2) & $96(88.9)$ & & 1 (ref) & & 1 (ref) \\
\hline $\mathrm{AC} / \mathrm{AA}$ & $14(6.8)$ & $12(11.1)$ & 0.192 & $0.583(0.260,1.310)$ & 0.360 & $0.665(0.278,1.592)$ \\
\hline \multicolumn{7}{|l|}{ rs1397529 } \\
\hline \multicolumn{7}{|l|}{ Female } \\
\hline $\mathrm{AA}$ & $556(89.8)$ & $555(84.3)$ & & 1 (ref) & & 1 (ref) \\
\hline $\mathrm{AC} / \mathrm{CC}$ & $63(10.2)$ & $103(15.7)$ & 0.004 & $0.611(0.437,0.853)$ & 0.003 & $0.605(0.432,0.847)$ \\
\hline \multicolumn{7}{|l|}{ Male } \\
\hline $\mathrm{AA}$ & $180(87.4)$ & $91(84.3)$ & & 1 (ref) & & 1(ref) \\
\hline $\mathrm{AC} / \mathrm{CC}$ & $26(12.6)$ & $17(15.7)$ & 0.446 & $0.773(0.399,1.498)$ & 0.993 & $0.997(0.486,2.045)$ \\
\hline
\end{tabular}

$P$ adj and $\mathrm{OR}[95 \% \mathrm{CI}]$ adj were adjusted for age and smoking. 
Table 7: Interaction between rs1347093, rs1397529 polymorphisms and smoking on lung cancer susceptibility

\begin{tabular}{lccccccc}
\hline SNP & Smoking & Cases & Controls & $\boldsymbol{P}$ & OR(95\%CI) & $\boldsymbol{P}$ adj & OR(95\%CI) adj \\
\hline rs1347093 & & & & & & & \\
AA/AC & Non-exposure & 43 & 82 & & $1(\mathrm{ref})$ & $1(\mathrm{ref})$ \\
CC & Non-exposure & 599 & 630 & 0.002 & $1.813(1.233,2.666)$ & 0.003 & $1.785(1.212,2.628)$ \\
AA/AC & Exposure & 14 & 4 & 0.001 & $6.674(2.070,21.524)$ & $<0.001$ & $9.202(2.704,31.318)$ \\
CC & Exposure & 169 & 50 & $<0.001$ & $6.446(3.966,10.474)$ & $<0.001$ & $9.007(4.877,16.637)$ \\
rs1397529 & & & & & & $1(\mathrm{ref})$ & $1(\mathrm{ref})$ \\
CC/AC & Non-exposure & 66 & 116 & & & \\
AA & Non-exposure & 576 & 596 & 0.001 & $1.699(1.230,2.347)$ & 0.002 & $1.679(1.215,2.322)$ \\
CC/AC & Exposure & 23 & 4 & $<0.001$ & $10.106(3.351,30.480)$ & $<0.001$ & $13.885(4.344,44.385)$ \\
AA & Exposure & 160 & 50 & $<0.001$ & $5.624(3.628,8.718)$ & $<0.001$ & $7.723(4.364,13.668)$ \\
\hline
\end{tabular}

$P$ adj and $\mathrm{OR}[95 \% \mathrm{CI}]$ adj were adjusted for age and gender.

Table 8: Crossover analysis of interaction between rs1347093, rs1397529 polymorphisms and smoking on lung cancer susceptibility

\begin{tabular}{lccc}
\hline Measure & Estimate & Lower & Upper \\
\hline rs1347093 & & & \\
RERI & -0.975 & -11.307 & 9.356 \\
AP & -0.108 & -1.255 & 1.038 \\
S & 0.891 & 0.282 & 2.814 \\
rs1397529 & & & \\
RERI & -6.845 & -15.522 & 1.832 \\
AP & -0.886 & -2.899 & 1.126 \\
S & 0.495 & 0.146 & 1.686 \\
\hline
\end{tabular}

was undefined, there were multiple studies about function of MIR217 in different types of tumors. The studies of Su J, Wang H, Zhou W, Li H, Shen L, Guo J, Zhu Y, Wang X, Li J, N. A. Schultz et al respectively linked MIR217 to hepatocellular carcinoma [25], gastric Cancer [26], breast cancer [27], renal cell carcinoma [28], osteosarcoma [29], lung cancer [30], glioma [31], esophageal carcinoma [32], ovarian cancer [33], pancreatic cancer [8] et al.

In our research, the newly-diagnosed patients were selected as cases, which could effectively avoid the Neyman bias. Given that the prevalent patients are more likely to change the exposure status of environmental factors and living habits, compared with the newlydiagnosed patients, which is beneficial to survive with lung cancer, the prevalent patients shouldn't be selected as the studying subjects. The cases and controls were selected from the same hospital, which could effectively avoid the Berkson bias. The observed genotype frequencies of rs1347093, rs1397529 among controls was in agreement with Hardy-Weinberg equilibrium, which means our studying subjects have good representativeness. In the present study, we carried out our studies, adjusting by gender, age and smoking. Above all of these could effectively improve the reliability of the results.

Our study firstly find that rs1347093, rs1397529 polymorphisms are associated with lung cancer risk in northeast Chinese population. However, some limitations should be considered before drawing a conclusion. Firstly, the present study is a hospital-based study, in which subjects in the control group are from the medical examination centers of the hospitals where our cases are selected. Therefore, controls may not be representative for the whole Chinese population very well. Secondly, in this study, all the subjects are from northeast China, thus a more diversified population should be selected to prove this results in the future study. 
Table 9: Logistic model of interaction between rs1347093, rs1397529 polymorphisms and smoking on lung cancer susceptibility

\begin{tabular}{|c|c|c|c|c|}
\hline Variables & Cases & Controls & Padj & OR(95\%CI $)$ adj \\
\hline \multicolumn{5}{|l|}{ rs1347093 } \\
\hline \multicolumn{5}{|l|}{ SNP } \\
\hline $\mathrm{AC} / \mathrm{AA}$ & 57 & 86 & & 1 (ref) \\
\hline $\mathrm{CC}$ & 768 & 680 & 0.003 & $1.785(1.212,2.628)$ \\
\hline \multicolumn{5}{|l|}{ smoking } \\
\hline no & 471 & 557 & & 1 (ref) \\
\hline yes & 68 & 82 & $<0.001$ & $9.202(2.704,31.318)$ \\
\hline interaction & & & 0.334 & $0.548(0.162,1.857)$ \\
\hline \multicolumn{5}{|l|}{ rs1397529 } \\
\hline \multicolumn{5}{|l|}{ SNP } \\
\hline $\mathrm{AC} / \mathrm{CC}$ & 89 & 120 & & 1 (ref) \\
\hline $\mathrm{AA}$ & 736 & 646 & 0.002 & $1.679(1.215,2.322)$ \\
\hline \multicolumn{5}{|l|}{ smoking } \\
\hline no & 471 & 557 & & 1 (ref) \\
\hline yes & 68 & 82 & $<0.001$ & $13.885(4.344,44.385)$ \\
\hline interaction & & & 0.061 & $0.331(0.104,1.052)$ \\
\hline
\end{tabular}

$P$ adj and $\mathrm{OR}[95 \% \mathrm{CI}]$ adj were adjusted for age and gender.

\section{MATERIALS AND METHODS}

\section{Subject data collection}

We carried out the hospital-based case-control study in Shenyang city which is located in the northeast China. Our study subjects consisted of 825 cases and 766 controls. All cases were diagnosed newly as lung cancer by the professional pathologists between March 2010 and January 2014. At the same time, we randomly selected people without a history of cancer as controls in the same hospital. In addition, we defined environmental exposure on the basis of our previous study [34]. Subjects who smoke more than 100 cigarettes in their lifetime were defined as smokers. Cases and controls were all unrelated ethic Han-Chinese people who lived in northeast and they had signed informed consent forms.

\section{DNA genotyping}

Firstly, we obtained a $5 \mathrm{ml}$ venous blood samples from every participant and isolated genomic DNA by phenol-chloroform method. A 7500 Fast Real-time PCR system (Applied Biosystems, Foster City, CA, USA) performed SNP genotyping to design PCR Taqman primers and probes (assay ID C__2076188_10 for rs1347093 and C__289707_10 for rs1397529), using
Applied Biosystems (CA, USA). The reaction conditions of the quantitative real-time PCR (q PCR) was as follows: $10 \mathrm{~min}$ at $95^{\circ} \mathrm{C}$ following by 47 cycles of $92^{\circ} \mathrm{C}$ for $30 \mathrm{~s}$ and $1 \mathrm{~min}$ at $60^{\circ} \mathrm{C}$. An ABI 7500 FAST Real-Time PCR System read the results of reaction, using the Sequence Detection Software. For the sake of quality control, the researchers were blinded to grouping state of subjects and we randomly selected $10 \%$ samples to carry out genotyping a second time. The results of the duplicated genotyping were $100 \%$ consistent with the former ones.

\section{Statistical analysis}

$\mathrm{T}$ test and $\chi^{2}$ test were carried out to examine the difference of demographic variables and smoking status between cases and controls. Hardy-Weinberg equilibrium (HWE) was examined by a goodness-of-fit $\chi^{2}$ test in the control group. The odds ratios (OR) and $95 \%$ confident intervals $(95 \% \mathrm{CI})$ were calculated by unconditional logistic regression analysis to estimate the relationship between SNP and the susceptibility of lung cancer. Multiplicative model and addictive model were conducted to evaluate the interaction between gene polymorphism and smoking status on lung cancer susceptibility. In multiplicative model, The odds ratios (OR) and 95\% confident intervals $(95 \% \mathrm{CI})$ were calculated in the logistic regression model to estimate the interaction. In addictive 
model, RERI (Relative Excess Risk due to Interaction), AP (Attributable Proportion due to Interaction), and S (Synergy Index) was used to estimate the interaction. When the $95 \%$ CI of S didn't include 1 and the $95 \% \mathrm{CI}$ of RERI and AP didn't include 0 , there was statistically significant interaction [35]. Almost analyses were adjusted by age, gender and smoking. All above analyses were twosided, and were carried out by SPSS software (vision 20.0) unless specified. The criterion of statistical significance was defined as $\mathrm{P}<0.05$.

\section{CONCLUSIONS}

The results of the present study demonstrate that significant association between rs1347093, rs1397529 polymorphism and susceptibility to lung cancer may exist in northeast Chinese population. There is no significant interaction between rs1347093, rs 1397529 polymorphism and smoking on susceptibility of lung cancer.

\section{CONFLICTS OF INTEREST}

We declare no conflicts of interest.

\section{ACKNOWLEDGMENTS AND GRANT SUPPORT}

We would like to thank all individuals in the case group and the control group for their participation. And we are grateful to all individuals at the hospitals in our study. This work is supported by grant no. 81502878 from National Natural Science Foundation of China and no.201501017 from the Doctoral Scientific Research Foundation of Liaoning Province.

\section{REFERENCES}

1. Siegel RL, Miller KD, Jemal A. Cancer statistics, 2015. CA Cancer J Clin. 2015; 65: 5-29. https://doi.org/10.3322/ caac. 21254.

2. Siegel RL, Miller KD, Jemal A. Cancer statistics, 2017. CA Cancer J Clin. 2017; 67: 7-30. https://doi.org/10.3322/ caac. 21387.

3. Torre LA, Bray F, Siegel RL, Ferlay J, Lortet-Tieulent J, Jemal A. Global cancer statistics, 2012. CA Cancer J Clin. 2015; 65: 87-108. https://doi.org/10.3322/caac.21262.

4. Jha P. Avoidable global cancer deaths and total deaths from smoking. Nat Rev Cancer. 2009; 9: 655-64. https://doi. org/10.1038/nrc2703.

5. Albright F, Teerlink C, Werner TL, Cannon-Albright LA. Significant evidence for a heritable contribution to cancer predisposition: a review of cancer familiality by site. BMC Cancer. 2012; 12: 138. https://doi. org/10.1186/1471-2407-12-138.
6. Brennan P, Hainaut P, Boffetta P. Genetics of lung-cancer susceptibility. Lancet Oncol. 2011; 12: 399-408. https://doi. org/10.1016/S1470-2045(10)70126-1.

7. Yin Z, Cui Z, Ren Y, Xia L, Li H, Zhou B. MiR-146a polymorphism correlates with lung cancer risk in Chinese nonsmoking females. Oncotarget. 2017; 8: 2275-83. https:// doi.org/10.18632/oncotarget.13722.

8. Schultz NA, Werner J, Willenbrock H, Roslind A, Horn T, Wøjdemann M, Johansen JS. MicroRNA expression profiles associated with pancreatic cancer. J Clin Oncol. 2011; 29: 153. https://doi.org/10.1200/jco.2011.29.4_suppl.153.

9. Szafranska AE, Doleshal M, Edmunds HS, Gordon S, Luttges J, Munding JB, Barth RJ, Gutmann EJ, Suriawinata AA, Pipas JM, Tannapfel A, Korc M, Hahn $\mathrm{SA}$, et al. Analysis of microRNAs in pancreatic fineneedle aspirates can classify benign and malignant tissues. Clin Chem. 2008; 54: 1716-24. https://doi.org/10.1373/ clinchem.2008.109603.

10. Nishida K, Hirano T. The role of Gab family scaffolding adapter proteins in the signal transduction of cytokine and growth factor receptors. Cancer Sci. 2003; 94: 1029-33. https://doi.org/10.1111/j.1349-7006.2003.tb01396.x.

11. Gu H, Neel BG. The 'Gab' in signal transduction. Trends Cell Biol. 2003; 13: 122-30. https://doi.org/10.1016/ S0962-8924(03)00002-3.

12. Burdon T, Stracey C, Chambers I, Nichols J, Smith A. Suppression of SHP-2 and ERK signalling promotes selfrenewal of mouse embryonic stem cells. Dev Biol. 1999; 210: 30-43. https://doi.org/10.1006/dbio.1999.9265.

13. Holgado-Madruga M, Emlet DR, Moscatello DK, Godwin AK, Wong AJ. A Grb2-associated docking protein in EGFand insulin-receptor signalling. Nature. 1996; 379: 560-4.

14. Nishida K, Yoshida $Y$, Itoh M, Fukada $T$, Ohtani $T$, Shirogane T, Atsumi T, Takahashi-Tezuka M, Ishihara K, Hibi M, Hirano T. Gab-family adapter proteins act downstream of cytokine and growth factor receptors and T- and B-cell antigen receptors. Blood. 1999; 93: 1809.

15. Yamasaki S, Nishida K, Yoshida Y, Itoh M, Hibi M, Hirano $\mathrm{T}$. Gab1 is required for EGF receptor signaling and the transformation by activated ErbB2. Oncogene. 2003; 22: 1546-56.

16. Fan Y, Yang F, Cao X, Chen C, Zhang X, Zhang X, Lin W, Wang X, Liang C. Gab1 regulates SDF-1-induced progression via inhibition of apoptosis pathway induced by $\mathrm{PI} 3 \mathrm{~K} / \mathrm{AKT} / \mathrm{Bcl}-2 / \mathrm{BAX}$ pathway in human chondrosarcoma. Tumour Biol. 2016; 37: 1141-9. https://doi.org/10.1007/ s13277-015-3815-2.

17. Bai R, Weng C, Dong H, Li S, Chen G, Xu Z. MicroRNA409-3p suppresses colorectal cancer invasion and metastasis partly by targeting GAB1 expression. Int J Cancer. 2015; 137: 2310-22. https://doi.org/10.1002/ijc.29607.

18. Chen D, Zhong F, Chen Y. Association of calcium/ calmodulin-dependent protein kinase kinase1 rs7214723 polymorphism with lung cancer risk in a Chinese 
population. Biosci Rep. 2017. https://doi.org/10.1042/ bsr20170762.

19. Xie K, Chen M, Zhu M, Wang C, Qin N, Liang C, Song C, Dai J, Jin G, Shen H, Lin D, Ma H, Hu Z. A polymorphism in miR-1262 regulatory region confers the risk of lung cancer in Chinese population. Int J Cancer. 2017; 141: 95866. https://doi.org/10.1002/ijc.30788.

20. Yin Z, Li H, Cui Z, Ren Y, Li X, Wu W, Guan P, Qian B, Rothman N, Lan Q, Zhou B. Polymorphisms in premiRNA genes and cooking oil fume exposure as well as their interaction on the risk of lung cancer in a Chinese nonsmoking female population. Onco Targets Ther. 2016; 9: 395-401. https://doi.org/10.2147/OTT.S96870.

21. Singh A, Singh N, Behera D, Sharma S. Polymorphism in XRCC1 gene modulates survival and clinical outcomes of advanced North Indian lung cancer patients treated with platinum-based doublet chemotherapy. Med Oncol. 2017; 34: 64. https://doi.org/10.1007/s12032-017-0923-4.

22. Ortiz-Padilla C, Gallego-Ortega D, Browne BC, Hochgrafe F, Caldon CE, Lyons RJ, Croucher DR, Rickwood D, Ormandy CJ, Brummer T, Daly RJ. Functional characterization of cancer-associated Gab1 mutations. Oncogene. 2013; 32: 2696-702. https://doi.org/10.1038/ onc.2012.271

23. $\mathrm{Hu} \mathrm{L}$, Liu R. Expression of Gab1 is associated with poor prognosis of patients with epithelial ovarian cancer. Tohoku J Exp Med. 2016; 239: 177-84. https://doi.org/10.1620/ tjem.239.177.

24. Chang CH, Chan PC, Li JR, Chen CJ, Shieh JJ, Fu YC, Chen $\mathrm{HC}, \mathrm{Wu}$ MJ. Gab1 is essential for membrane translocation, activity and integrity of mTORCs after EGF stimulation in urothelial cell carcinoma. Oncotarget. 2015; 6: 1478-89. https://doi.org/10.18632/oncotarget.2756.

25. Su J, Wang Q, Liu Y, Zhong M. miR-217 inhibits invasion of hepatocellular carcinoma cells through direct suppression of E2F3. Mol Cell Biochem. 2014; 392: 289-96. https://doi. org/10.1007/s11010-014-2039-x.

26. Wang H, Dong X, Gu X, Qin R, Jia H, Gao J. The microRNA-217 functions as a potential tumor suppressor in gastric cancer by targeting GPC5. PLoS One. 2015; 10: e0125474. https://doi.org/10.1371/journal.pone.0125474.

27. Zhou W, Song F, Wu Q, Liu R, Wang L, Liu C, Peng Y, Mao S, Feng J, Chen C. miR-217 inhibits triple-negative breast cancer cell growth, migration, and invasion through targeting KLF5. PLoS One. 2017; 12: e0176395. https://doi. org/10.1371/journal.pone.0176395.

28. Li H, Zhao J, Zhang JW, Huang QY, Huang JZ, Chi LS, Tang HJ, Liu GQ, Zhu DJ, Ma WM. MicroRNA-217, down-regulated in clear cell renal cell carcinoma and associated with lower survival, suppresses cell proliferation and migration. Neoplasma. 2013; 60: 511-5. https://doi. org/10.4149/neo_2013_066.

29. Shen L, Wang P, Yang J, Li X. MicroRNA-217 regulates WASF3 expression and suppresses tumor growth and metastasis in osteosarcoma. PLoS One. 2014; 9: e109138. https://doi.org/10.1371/journal.pone.0109138.

30. Guo J, Feng Z, Huang ZA, Wang H, Lu W. MicroRNA-217 functions as a tumour suppressor gene and correlates with cell resistance to cisplatin in lung cancer. Mol Cells. 2014; 37: 664-71. https://doi.org/10.14348/molcells.2014.0121.

31. Zhu Y, Zhao H, Feng L, Xu S. MicroRNA-217 inhibits cell proliferation and invasion by targeting Runx 2 in human glioma. Am J Transl Res. 2016; 8: 1482-91.

32. Wang X, Li M, Wang Z, Han S, Tang X, Ge Y, Zhou L, Zhou C, Yuan Q, Yang M. Silencing of long noncoding RNA MALAT1 by miR-101 and miR-217 inhibits proliferation, migration, and invasion of esophageal squamous cell carcinoma cells. J Biol Chem. 2015; 290: 3925-35. https:// doi.org/10.1074/jbc.M114.596866.

33. Li J, Li D, Zhang W. Tumor suppressor role of miR-217 in human epithelial ovarian cancer by targeting IGF1R. Oncol Rep. 2016; 35: 1671-9. https://doi.org/10.3892/ or.2015.4498.

34. Ren Y, Yin Z, Li K, Wan Y, Li X, Wu W, Guan P, Zhou B. TGF $\beta-1$ and TGFBR2 polymorphisms, cooking oil fume exposure and risk of lung adenocarcinoma in Chinese nonsmoking females: a case control study. BMC Med Genet. 2015; 16: 22. https://doi.org/10.1186/ s12881-015-0170-5.

35. Quan X, Yin Z, Fang X, Zhou B. Single nucleotide polymorphism rs3124599 in Notch1 is associated with the risk of lung cancer in northeast Chinese non-smoking females. Oncotarget. 2017; 8: 31180-6. https://doi. org/10.18632/oncotarget.16101. 